\title{
Biocompatibility of natural latex implanted into dental alveolus of rats
}

\author{
Cláudia A.C.A Balabanian ${ }^{1)}$, Joaquim Coutinho-Netto ${ }^{2)}$, \\ Teresa L. Lamano-Carvalho ${ }^{1)}$, Suzie A. Lacerda ${ }^{1)}$ and Luiz G. Brentegani ${ }^{1)}$ \\ ${ }^{1)}$ Department of Morphology, Stomatology and Physiology, School of Dentistry, \\ University of São Paulo-USP, Ribeirão Preto, Brazil \\ ${ }^{2)}$ Department of Biochemistry and Immunology, School of Medicine, \\ University of São Paulo-USP, Ribeirão Preto, Brazil
}

(Received 27 February and accepted 9 September 2006)

\begin{abstract}
The present study investigated the biocompatibility of a biopolymer based on vegetable latex extracted from the Hevea brasiliensis rubber tree, implanted into the bony alveolar cavity after dental extraction in rats. A granule of latex (area $=0.25 \pm 0.04$ $\mathbf{m m}^{2}$ ) was implanted inside the alveolus immediately after extraction of the upper right incisor, and the animals were sacrificed 7, 21 and 42 days after the procedure. The hemi-maxillas were decalcified and processed for embedding in paraffin to obtain semiserial longitudinal sections 5 um thick, and then stained with hematoxylin-eosin. The latex granule was observed in the cervical third of the alveolus without any foreign body reaction, or persistence of the initial acute inflammatory reaction. Bone repair in the areas adjacent to the material was quantified, and a decrease was noted in the thickness of the fibrous capsule surrounding the implants from $92.8 \pm 9.3 \mu \mathrm{m}$ on day 7 to $9.4 \pm 1.8 \mu \mathrm{m}$ on day 42 (ANOVA, $P=0.01$ ). The quantitative data confirmed acceleration of bone formation (statistically significant at 5\%) in parallel with a decrease of connective tissue in the areas around the implants. These results show that the tested material is biologically compatible, and progressively integrated
\end{abstract}

Correspondence to Dr. Luiz Guilherme Brentegani, Departamento de Morfologia, Estomatologia e Fisiologia, Faculdade de Odontologia de Ribeirão Preto-USP, Av. do Café, s/n - 14040904, Ribeirão Preto, SP, Brasil

Tel: +55-16-3602-4013

Fax: +55-16-3633-0999

E-mail: lgb@forp.usp.br into the alveolar bone, simultaneously accelerating bone formation and playing an important role in the healing process. (J. Oral Sci. 48, 201-205, 2006)

Keywords: natural latex; biocompatibility; implant; alveolar repair.

\section{Introduction}

Over the last few years, a number of studies have focused on the development of alloplastic materials that possess characteristics of both biocompatibility and osseointegration and promote the repair of bone defects.

Recent reports have described promising results obtained with a biopolymer from extracted vegetable latex of the Hevea brasiliensis rubber tree, which has a structure composed of polylysine chains and proteins similar to that of cellular membranes. The application of this natural latex in membrane form has been shown to be not only biocompatible but also to stimulate angiogenesis, cellular adhesion and the formation of extracellular matrix (1), promoting the replacement and regeneration of tissue, and accelerating wound healing in cutaneous tissue (2), the pericardium (3), the esophagus and abdominal wall (1), the tympanum (4), blood vessels (5), and ocular conjuctiva (6), without producing signs of hypersensitivity (2).

The purpose of the present study was to test the biocompatibility of this natural latex for the repair of bone defects in dental alveoli as an alternative material that is cheap and easy to obtain, and can be used in dental surgeries for placement of dental support implants. 


\section{Material and Methods}

Male Wistar albino rats weighing 250-300 g were anesthetized with an intraperitoneal injection of 2.2.2tribromoethanol (Sigma-Aldrich, St. Louis, MO, USA) at a dose of $25 \mathrm{mg} / 100 \mathrm{~g}$ body weight. Under sterile conditions, the upper right incisors were extracted using forceps, after disconnection of the surrounding gingiva and luxation with an enamel hatchet with a cutting edge. Immediately after the surgery, one granule of latex (area $=0.25 \pm 0.04 \mathrm{~mm}^{2}$ ) was implanted inside the alveolus and the soft tissues were sutured with nylon monofilament. A single 0.2-ml intramuscular dose of antibiotic (Veterinary Pentabiotic, Fontoura-Wyeth, São Paulo, Brazil) was administered to each rat. The animals were sacrificed by an overdose of anesthetic 7,21 and 42 days after extraction $(\mathrm{n}=10$ per group). The mandibles were separated from the maxillas, and the right hemi-maxilla was separated from the left one by a sagittal incision along the intermaxillary suture. The maxillary halves were fixed in buffered $(\mathrm{pH}$ 7) $10 \%$ formaldehyde solution for $24 \mathrm{~h}$. The specimens were then washed in running water and decalcified by soaking in a solution containing $20 \%$ sodium citrate and $30 \%$ formic acid for 6 days. This solution was replaced every 2 days and neutralized with 5\% sodium sulfate. The specimens were then dehydrated by soaking them in increasingly concentrated ethanol solutions: $70 \%$ overnight, then $80 \%, 85 \%, 90 \%$, and $95 \%$ for $2 \mathrm{~h}$ each, until $100 \%$. The specimens were then processed with xylol and embedded in paraffin. Longitudinal semi-serial sections $5 \mu \mathrm{m}$ thick were stained with hematoxylin and eosin (HE). All the procedures were conducted in accordance with ethical principles for animal research, as approved by institutional guidelines.

\section{Natural latex granules}

The natural latex was extracted from the Hevea brasiliensis rubber tree in the traditional way using a spiral incision, 60 to $90 \mathrm{~cm}$ above ground level, through the phloem of the tree. The milky liquid natural latex was allowed to drain, and a small amount of ammonia was applied to the distal end of the spiral to assist the flow of the latex. Ammonia was also added to the collection receptacle to prevent coagulation of the latex. After collection, the latex was centrifuged to decrease the amount of natural proteins, many of which are responsible for allergic reactions (7). After centrifugation, the supernatant was discarded, and the residue was made into granules (area $=0.25 \pm 0.04 \mathrm{~mm}^{2}$ ) for implantation inside the alveolus.

\section{Histometric analysis of the alveoli}

A Leica DM LB2 optical microscope with a Leica DFC
280 digital video camera (Leica Microsystems Wetzlar $\mathrm{GmbH}$, Wetzlar, Germany) was used to capture the images, and the images were processed using the Leica Qwin program (Leica Imaging Systems, Cambridge, England). The thickness of the fibrous capsule $(\mu \mathrm{m})$ around the implants and the volume fraction (\%) of bone trabeculae in areas adjacent to the granule were calculated by a differential point-counting method, as described previously (8-10).

Two thousand points lying on connective tissue and bone trabeculae were counted per alveolus in trial areas contiguous to the implants. The thickness of the fibrous capsule around the implants was estimated by direct measurement of ten equidistant points per alveolus $(\mathrm{n}=$ $10)$.

\section{Results}

Histological examination showed natural latex granules, which had not been resorbed, in the cervical third of the alveolus with no persistent inflammation or foreign-body reaction (Fig. 1). On day 7, histological and histometric evaluations of the trial areas adjacent to the implants showed that the latex granules were encircled by a conspicuous capsule $(92.8 \pm 9.3 \mu \mathrm{m})$ (Fig. 3) surrounded by immature connective tissue that was rich in fibroblasts and newly formed capillaries (Fig. 2A) in contact with newly formed bone tissue consisting of delicate trabeculae and new connective tissue containing many active
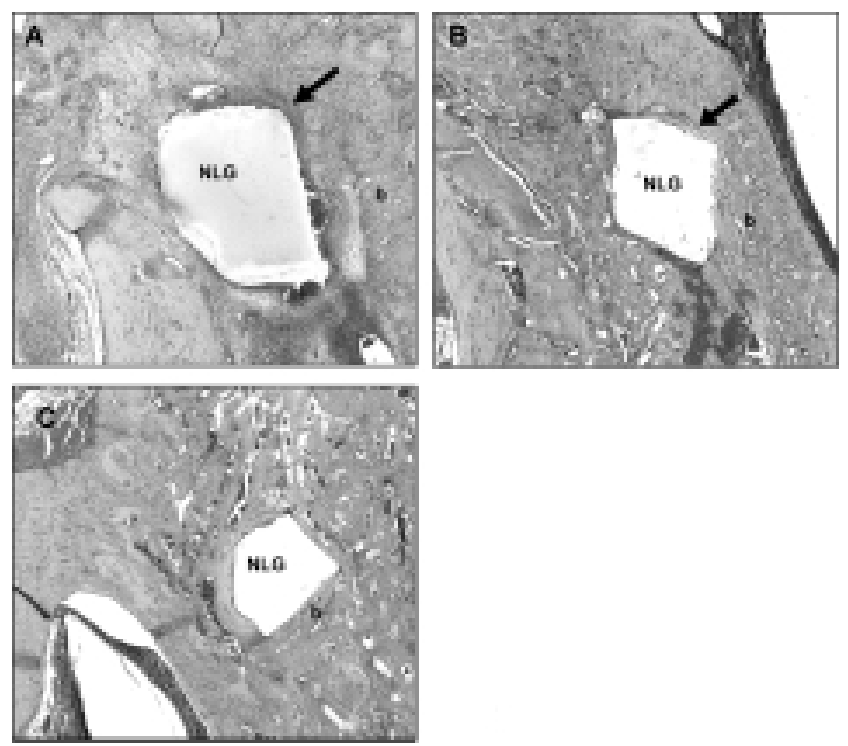

Fig. 1 Light micrographs of areas around natural latex granules (NLG) implanted into the cervical third of the rat dental alveolus. The implants are encircled by a connective tissue capsule (arrow) and the adjacent areas are occupied by bone (b). A: 7 days, B: 21 days, C: 42 days. Magnification: $\times 62.5$; HE. 
osteoblasts and new vessels. Table 1 shows that (on day 7) more newly formed bone (statistically significant at 5\%) was present in the animals bearing the latex implants than in control animals without the implants. On day 21, the capsule was thinner $(23.1 \pm 3.3 \mu \mathrm{m})$, and most of the test area was occupied by mature bone (Fig. 2B and Table 1). By day 42 , the capsule thickness was reduced to $9.4 \pm 1.8$ $\mu \mathrm{m}$, and the test area was almost totally filled with bone, which was in close contact with the implants at some sites (Fig. 2C and Table 1). On days 21 and 42 after implantation, the percentage of bone was the same in both experimental groups (Table 1).

Quantitative data confirmed the progressive formation of bone that paralleled the decrease in the volume fraction of the connective tissue in the areas adjacent to the implants (Fig. 3 and Table 1).

\section{Discussion}

Clinical and experimental studies have investigated the biocompatibility of materials for implantation in areas of the maxilla and mandible of humans and animals based on histological, histometric and radiographic evaluations with the intention of accelerating bone repair and reducing the time required for placement of implants for dental support. Various materials have been used to attain this
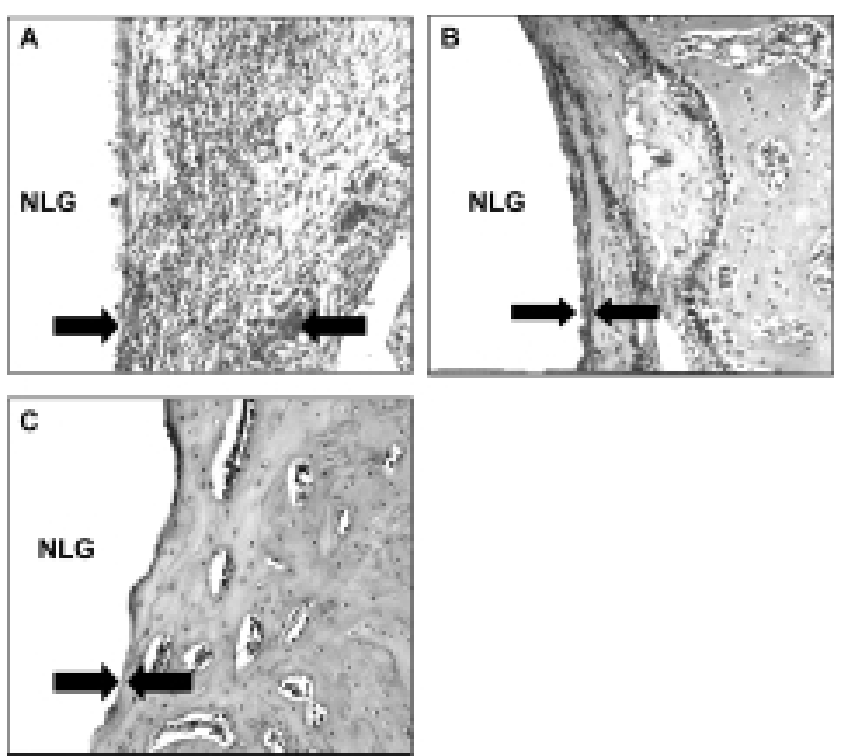

Fig. 2 Trial areas around natural latex granules (NLG) implanted into the rat dental alveolus.

A: At 7 days, the material is encircled by an inflammatory capsule (arrow) and surrounded by granulation tissue; B: At 21 days, a thin fibrous capsule (arrow) encircles the granules, which in turn are surrounded by newly formed trabecular bone; C: At 42 days, mature bone is in close contact with the material in many places. Magnification: $\times 200$; HE. objective, including ceramics, polymers, composites, bioactive glass, enamel matrix proteins, bone morphogenetic protein, autogenous or homogeneous, or heterogeneous, bone, non-decalcified or decalcified or lyophilized bovine bone, mineral porous bone, plateletenriched plasma, and alendronate. Many of them have shown only limited effectiveness for bone repair, and in some cases, specific disadvantages.

Any foreign material placed inside living tissues provokes a reaction, whose intensity and duration determine the degree of biocompatibility. That is, biocompatibility is "a state of mutual coexistence between a material and the physiological environment, with no mutually unfavorable effect" (11).

A number of biopolymers have been tested, and the results have demonstrated clear differences among the materials in terms of foreign body reaction around the implant and growth of fibrous tissue and bone.

Table 1 Volume fraction (\%) of bone trabeculae on days 7 , 21 and 42 after tooth extraction in trial areas in lateximplanted and control (non-implanted) groups (mean \pm SEM for 7 rats per group)

\begin{tabular}{ccc}
\hline Period (days) & Control (\%) & Latex $(\%)$ \\
\hline 07 & $17.7 \pm 2.1$ & $26.7 \pm 3.1^{*}$ \\
21 & $53.8 \pm 2.5$ & $55.1 \pm 3.2$ \\
42 & $73.8 \pm 1.9$ & $74.3 \pm 2.2$ \\
\hline
\end{tabular}

\section{* Values statistically significant (5\%)-ANOVA}

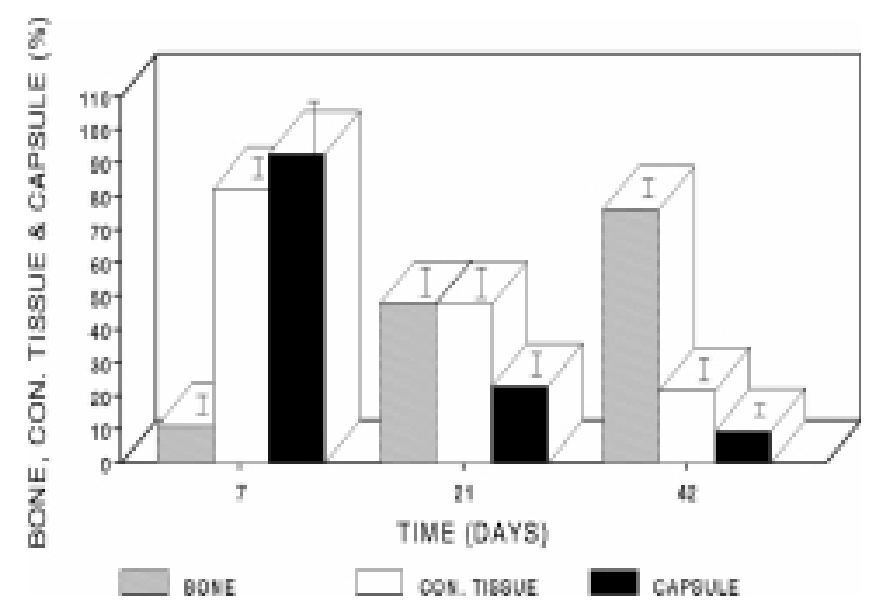

Fig. 3 Volume fraction (\%) of bone trabeculae (Bone), connective tissue (con. tissue), and capsule estimated on days 7, 21 and 42 after tooth extraction in trial areas around natural latex granules implanted into the rat dental alveolus (mean \pm SEM for 7 rats per group). 
Osseointegration is defined as a structural and functional connection between organized bone and the surface of an implanted material (12). Fibro-osseous integration (indirect osseointegration) occurs when a fibrous capsule surrounds the material, and this is only acceptable during the initial period after implantation (13) because encapsulated implants are considered unstable (14).

In the present study we investigated the biocompatibility of a biopolymer from the extracted vegetable latex of the Hevea brasiliensis rubber tree using a model of alveolar repair in rats. Histological examination of the extraction sockets revealed a pattern of normal repair with characteristics similar to those reported in previous studies, including those from our laboratory (8-10).

Histometric evaluation of the areas close to the implant during the initial 7 days demonstrated progressive and accelerated osteogenesis in the animals bearing latex implants, accompanied by a decrease in the thickness of the fibrous capsule. Long-term evaluation revealed neither a foreign-body reaction nor a persistent inflammatory reaction, and on day 42 , close contact between bone and the implants was observed at many sites.

Although the present investigation was not intended to examine the mechanisms by which the presence of latex altered the process of bone repair, it is reasonable to assume that the latex may have interfered with local control of new bone formation.

The angiogenic effect induced by the biopolymer may be due to the direct action of an angiogenic protein present in the latex of Hevea brasiliensis, which is slowly liberated from the granule (15-18). Our results showed that the tested material was biologically compatible, being integrated progressively into the alveolar bone and accelerating the process of bone formation during the initial period of bone repair. Therefore we conclude that latex from rubber trees can be used as a biomaterial, opening new possibilities for applications of this material in the medical field.

\section{Conclusion}

Granules of natural latex implanted inside the alveolar sockets of rats immediately after dental extraction show biocompatibility and become integrated with the alveolar bone, simultaneously accelerating bone formation, and playing an important role in the healing process.

\section{Acknowledgments}

We wish to thank Adriana M. G. Silva, Gilberto André e Silva, Antonio de Campos and Edna A. S. Moraes for technical assistance. The material for the implants was kindly donated by Dr. Joaquim Coutinho-Netto.

\section{References}

1. Mrué F, Coutinho-Netto J, Ceneviva R, Lachat JJ, Thomazini JA, Tambelini H (2004) Evaluation of the biocompatibility of a new biomembrane. Mat Res 7, 277-283

2. Frade MAC, Valverde RV, Campos de Assis RV, Coutinho-Netto J, Foss NT (2001) Chronic phlebopathic cutaneous ulcer: a therapeutic proposal. Int J Dermatol 40, 237-240

3. Sader SL, Coutinho-Netto J, Barbieri-Neto J, Mazzetto SA, Alves P Jr, Vanni JC, Sader AA (2000) Substituição parcial do pericárdio de cães por membrana de látex natural. Rev Bras Cir Cardiovasc 15, 338-344 (in Portuguese)

4. Oliveira JAA, Hyppolito MA, Coutinho-Netto J, Mrué F (2003) Myringoplasty using a new biomaterial allograft. Rev Bras Otor 69, 649-655 (in Portuguese)

5. Thomazini JA, Freitas MAS, Lachat JJ, CoutinhoNetto J, Cherri J (2001) Structural and ultrastructural study of the luminal surface of femoral arteries of dogs submitted at arterioplasty with implants of prosthesis manufactured from natural latex of Hevea Brasiliensis. Acta Microscopica, Suppl B, 263-264

6. Pinho ECCM, Sousa SJF, Schaud F, Lachat JJ, Coutinho-Netto J (2004) Uso experimental da biomembrana de látex na reconstrução conjuntival. Arq Bras Oftalmol 67, 27-32 (in Portuguese)

7. Ellis C (1990) Allergic and immune reactions. Practitioner 234, 1054-1058

8. Lamano-Carvalho TL, Bombonato KF, Brentegani LG (1997) Histometric analysis of rat alveolar wound healing. Braz Dent J 8, 9-12

9. Brentegani LG, Bombonato KF, Lamano-Carvalho TL (1997) Histologic evaluation of the biocompatibility of glass-ionomer cement in rat alveolus. Biomaterials 18, 137-140

10. Brentegani LG, Bombonato KF, Lamano-Carvalho TL (1996) Immediate implantation of glass-ionomer cement granules increases osteogenesis during rat alveolar wound healing. J Nihon Univ Sch Dent 38, 141-145

11. Boss JH, Shajrawi I, Aunullah J, Mendes DG (1995) The relativity of biocompatibility. A critique of the concept of biocompatibility. Isr J Med Sci 31, 203209

12. Adell R, Lekholm U, Rockler B, Branemark PI (1981) A 15-year study of osseointegrated implants in the treatment of the edentulous jaw. Int J Oral Surg $10,387-416$

13. Weiss CM (1986) Tissue integration of dental 
endosseous implants: description and comparative analysis of the fibro-osseous integration and osseous integration system. J Oral Implantol 12, 169-214

14. Albrektsson T, Sennerby L (1990) Direct bone anchorage of oral implants: clinical and experimental considerations of the concept of osseointegration. Int J Prosthodont 3, 30-41

15. Soares SC, Cursi IB, Andrade FF, Campos EM, Carvalho MTF, Coutinho-Netto J, Foss NT, Frade MA (2004) Úlcera de Perna: tratamento e cicatrização. HU Rev, 30, 16-19 (in Portuguese)

16. Potério-Filho J, Silveira SAF, Potério GMB, Mrué F, Coutinho-Netto J (1999) O uso do latex natural com polilisina $0.1 \%$ na cicatrização de úlceras isquêmicas. Rev Bras Angiol e Cir Vasc 15, 156 (abstract) (in Portuguese)

17. Frade MAC, Cursi IB, Andrade FF, Coutinho-Netto J, Barbetta FM, Foss NT (2004) Management of diabetic skin wounds with a natural latex biomembrane. Med Cutan Iber Lat Am 32, 157-162

18. Thomazini JA, Mrué F, Lachat JJ, Zborowski AC, Duran JHR, Ceneviva R, Coutinho-Netto J (1997) Morphological and biochemical characterization of a prosthesis manufactured from natural latex of Hevea brasiliensis for medical utilization. Acta Microscopica 6, Suppl B, 798-799 